\title{
Rasuras disciplinares e amputação de fazeres
}

José Damico*

\begin{abstract}
Resumo: O ensaio faz uma reflexão sobre algumas possibilidades de educadores físicos atuarem no campo da saúde coletiva a partir da lógica da integralidade na saúde. Procura colocar em tensão alguns pontos centrais na lógica hegemônica dos discursos voltados à atividade física e à saúde na área de educação física. Sugere que a superação desse quadro demanda uma cirurgia de amputação do saber disciplinar que estabelece relações sujeito-objeto para que possamos desmedicalizar a demanda e escutar a subjetividade que está na queixa dos indivíduos.
\end{abstract}

Palavras-chave: educação física, saúde coletiva, integralidade e escuta.

\section{RASURAS DISCIPLINARES E AMPUTAÇÃO DE FAZERES}

Não é de hoje que parte do movimento sanitário brasileiro vem propondo a reorganização dos serviços de saúde como um dos principais pressupostos da produção do cuidado, "um processo de trabalho no qual o usuário seja o centro da atenção através de relações

\footnotetext{
"Professor Adjunto do Curso de Educação Física (FURG/Instituto de Educação) e Docente do Programa de Pós-Graduação em Educação e Ciências (FURG/UFRGS/UFSM). E-mail: zdamico@yahoo.com.br

${ }^{1}$ As metáforas utilizadas neste ensaio buscam ampliar os sentidos, ao invés de fixá-los, ainda que, desde uma longa tradição iniciada com Aristóteles, o emprego deste recurso na produção científica e nos relatos dos pacientes aos médicos seja criticada, por ser considerada fútil ou dispensável. No entanto, como se trata de um artigo que dialoga com o campo da saúde, preferi seguir Freud (1983, p. 123), que, ao discutir o sintoma histérico, amplia seu caráter discursivo, ao ponto de compará-lo com a poesia, nas suas palavras "como um príncipe disfarçado de mendigo." Tal elaboração de Freud impactou e redimensionou a prática clínica irremediavelmente, o que se conecta com o sentido geral do texto na direção de uma clínica ampliada. Quanto às funções que a metáfora pode exercer na clínica, bem como a função metafórica do terapeuta/analista, ver Zanello (2007).
} 
acolhedoras, capazes de produzir vínculo, em um processo produtivo que aposta nas tecnologias mais relacionais para a assistência aos usuários" (FRANCO; MERHY, 2005, p. 183). No entanto, a saúde coletiva também é um campo de disputas, em que outras forças agem na direção contrária, através de toda uma produção acadêmica voltada para a construção de outros significados para a lógica assistencial e, consequentemente, para o conhecimento sobre o processo saúde-doença.

Exemplo disso é um segmento da literatura científica no campo biomédico, que vem publicando uma série de estudos que transforma alimentos ou hábitos que outrora faziam parte das experiências culturais das pessoas em remédios. Basta que prestemos atenção a alguns desses enunciados, como, por exemplo, os que se encontram na sequência.

Pesquisadores da Universidade de Pensilvânia (EUA) reuniram evidências, oriundas de 66 estudos já publicados, de que o consumo moderado de chá e chocolate está fortemente associado à redução dos riscos de problemas cardiovasculares. Isso ocorreria porque são alimentos ricos em flavonóides, substâncias que têm efeitos antioxidantes (KRIS-ETHERTON, 2005).

Nessa mesma linha, há estudos que apontam os benefícios do vinho para a saúde cardiovascular, estabelecendo relações com a enzima polifenol, presente na uva e tida como grande auxiliar na "limpeza" dos vasos sanguíneos (SCARMEAS; LEVY; STERN, 2001). Seguindo esse raciocínio, o estudo do Taub Institute, da Universidade de Colômbia, analisou atividades de lazer, como ler livros e revistas, ir ao cinema ou visitar amigos, indicando que podem ser uma maneira eficiente de prevenir o Mal de Alzheimer (BAREFOOT, 2002). Segundo a pesquisa, pessoas que investem no próprio lazer de forma constante têm um risco de desenvolver a doença $38 \%$ menor do que pessoas que não praticam esse tipo de atividades. 
Todos esses discursos validados por comunidades científicas e transmitidos para a população pela mídia têm em comum a receita "certa" para a busca da saúde perfeita. Esses modelos de produções/ prescrições têm estimulado vários núcleos profissionais a acreditarem que o processo de adoecimento estaria ligado a simples escolhas. Como nos discursos vinculados às estratégias de uma melhor qualidade de vida, de promoção da saúde, bem como da adoção de estilos de vida mais saudáveis. Tais discursos se apresentam como o modo mais eficaz de informar os indivíduos sobre as condutas que deverão seguir, caso tenham objetivo de viver mais e melhor. As estratégias de prevenção e promoção da saúde para a população de uma forma geral veiculam discursos que destacam os riscos e, em contrapartida, os benefícios de adotar determinadas prescrições.

Apesar da força dos discursos que atendem a lógica biomédica, principalmente no âmbito da educação física, opto neste ensaio, por um outro caminho, que está na contramão de qualquer perspectiva totalizante. Trata-se de uma reformulação do modo como se atende as pessoas. Segundo as ponderações de Paulo Fensterseifer:

Entre as perspectivas que visualizamos, está a necessidade de objetivarmos experiências, sistematizando conhecimentos da prática profissional que possam ser apropriados pelos profissionais em formação. $\mathrm{O}$ que demandaria um direcionamento das investigações para questões do universo da intervenção, bem como o desafio aos profissionais para que produzam registros de suas experiências (FENSTERSEIFER, 2006, p.95).

É desafiado pelo autor acima, que, tratarei, ao longo deste texto, de responder parcialmente as provocações de Fensterseifer, a partir da apresentação de algumas das relações de força, das contingências, das linhas de fuga que podem permitir que nós, da educação física, possamos produzir, olhar e narrar nossas experiências na assistência à saúde a partir da lógica da integralidade. 


\section{BUSCANDO AS CONTINGÊNCIAS}

Há alguns anos atrás, a educação física foi catapultada, por medida normativa, de uma disciplina da área das ciências humanas e sociais, ou seja, do campo da educação, para o campo da saúde. Certamente, esse processo, que podemos chamar de migratório e que tem sua culminância mais formal com a resolução 218/CNS/ $1997^{2}$, tem produzido importantes efeitos de verdade e reconfigurado sobremaneira as disputas por hegemonia na área. Essa disputa pode ser representada sinteticamente por referenciais de dois grupos. Um deles composto por aqueles que têm suas "produções alicerçadas na perspectiva epidemiológica e que advogam o incremento de atividade física regular como estratégia de redução de determinados fatores de riscos e agravos - principalmente - para as ditas doenças crônico-degenerativas" (BILIBIO; DAMICO, 2011, p. 96). E outro grupo que tem criticado esse argumento anterior sustentando suas posições com base na crítica de um individualismo capitalista que estaria ligado à lógica de mercado e à consequente moralização das condutas.

As condições de possibilidade, na contemporaneidade, para o retorno formal da educação física para a área da saúde encontram suas bases num projeto que articula um conjunto de intervenções visando mudanças no comportamento dos indivíduos, principalmente indicando estilos de vida e, por conseguinte, hábitos que devem ser cultivados, dentre os quais destacam-se os exercícios físicos e dietas adequadas. Assim, o corpo como projeto é um construto contemporâneo, pensável, sobretudo no contexto da racionalidade neoliberal, como algo que pode ser constantemente aperfeiçoado, melhorado e modificado.

\footnotetext{
${ }^{2} A$ década final do século $X X$ foi marcante para a área de Educação Física em decorrência da promulgação da nova LDB (Lei $n{ }^{\circ} 9.394 / 96$ ), do reconhecimento do profissional no âmbito da área de saúde (Resolução no 218/CNS/1997), da regulamentação da profissão em Educação Física (Lei n ⒐696/1998) e, decorrente disso, a criação do sistema CONFEF/CREF (HADDAD, 2006).
} 
Para David Castiel (2003), o objetivo dos programas de promoção da saúde é motivar posturas pró-ativas dos indivíduos com relação à saúde, por meio de cuidados de saúde nãoinstitucionalizados. De acordo com a Organização Mundial de Saúde (OMS), a promoção da saúde foi conceituada como o "processo de capacitar as pessoas a aumentarem o controle sobre sua saúde, aprimorando-a" (OLIVEIRA, 2005, p. 425).

A promoção da saúde, mediante sua ênfase no individualismo, incentiva a busca de uma autonomia individual. Trata-se aqui do principal paradoxo das políticas de promoção da saúde: ter como meta a promoção da autonomia individual no tocante às escolhas em saúde e circunscrever a saúde a definições médicas, ou seja, escolhas podem e devem ser feitas, desde que sejam as corretas do ponto de vista médico. Exemplos disso são as campanhas de prevenção e promoção da saúde com relação ao sedentarismo, ao tabagismo, à obesidade e ao HIV/AIDS, que procuram promover mudanças de comportamentos, atitudes e práticas que passam a ganhar destaque em prol de um estilo de vida saudável (FRAGA, 2006).

A política de responsabilização do indivíduo ganha, no agora "novo profissional" de educação física, um dos personagens mais atuantes e vigilantes. Isso, de uma forma mais crítica, pauta a saúde das pessoas por princípios baseados na autonomia e na retórica do risco individual, em franca negação de um processo mais amplo de discussão das condições ambientais e da desigualdade econômica e social, portanto, negação da cidadania e do contrato social.

Entretanto, o que quero chamar a atenção, neste ensaio, é de como podemos nos inserir nas equipes de saúde, por outro viés, em que nossos atos de saúde possam estar constituindo novidades se utilizarmos outras ferramentas de trabalho. 


\section{AMPUTANDO $^{3}$ FAZERES EM BUSCA DE LINHAS DE FUGA}

O desafio estaria em passar deste campo de certezas e de regularidades que a lógica da promoção/prevenção da saúde e do combate das doenças crônicas degenerativas insiste em assegurar para o campo da imprevisibilidade radical da vida cotidiana. Aliás, esse não é um percurso tranquilo, uma vez que implica, no mínimo, admitir os limites de qualquer saber pré-estruturado.

Em muitas ocasiões, durante minhas vivências profissionais em unidades básicas e hospitais, pude presenciar reações iradas de "especialistas" quando estes eram confrontados/instigados a intervirem a partir de lógicas diferentes daquelas com que estavam acostumados - como se estivessem sendo amputados do seu saberfazer. Proponho um exercício coletivo de amputação, análogo à epidemia da perda de visão proposta na obra Ensaio sobre a cegueira, de José Saramago. Imaginemos professores de educação física, médicos, enfermeiros, fisioterapeutas, psicólogos, assistentes sociais etc, sem algum dos membros/ferramentas de seu saber-fazer. Esse/ $\mathrm{s}$ membro/s é/são amputado/s pelo vírus da integralidade.

A metáfora da amputação, retirada do romance do autor português, serve para que possamos pensar como trabalhadores de instituições pretensamente curativas se sentem quando sua ferramenta de trabalho, seus membros, não pode restabelecer a funcionalidade de um órgão.

Muitas das preocupações de educadores físicos, quando estes têm sido chamados a intervir na saúde coletiva, se colocam numa perspectiva de torná-la curativa. Seria como se soubéssemos quais as atividades lúdicas ideais para que cada indivíduo recuperasse sua saúde, ou quais exercícios ginásticos seriam adequados para minimizar o padecimento dos sujeitos ou, ainda, as respostas objetivas e positivas de cada pedido ou pergunta sobre a possível cura.

\footnotetext{
${ }^{3} \mathrm{~A}$ metáfora da amputação é utilizada neste texto como corte ou perda da especificidade profissional dos trabalhadores que militam na saúde coletiva.
} 
Essa lógica de intervenção indica que o núcleo da educação física, ao propor suas intervenções na produção do cuidado em saúde, tem capturado práticas bem tradicionais e corporativas. Essa tendência de adotar o mesmo modus operandi da tradição médica hegemônica se explica pela força representativa que a categoria médica tem nas maneiras de construir atos de saúde.

Trata-se, no entanto, de pensar em ir além da ideia de considerar o usuário em atendimento como um portador de necessidade, como parte ou fragmento de um corpo com problemas biológicos, como um ser sem subjetividade, sem intenções, sem vontades, sem desejos. A educação física e outros profissionais, ao se desterritorializarem dos seus núcleos profissionais e ao assumirem a integralidade do cuidado como a sua principal ferramenta, podem abrir-se as possibilidades de outros fazeres, aqueles que são possíveis de serem produzidos nos encontros e somente no encontro entre cuidador e usuário

O cuidado, enquanto uma ferramenta fundamental com que opera a integralidade em saúde, permite perceber que as situações ocorridas nos encontros estão presentes para todos os núcleos profissionais, mesmo para aqueles que tentam torná-la seu objeto exclusivo de ação.

Voltando à metáfora da amputação: seria como "fazer um bem médico, isto quer dizer introduzir saúde aí onde há doenças, mas fazê-lo aí justamente onde há um tipo de doença que não se pode curar" (JERUZALINSKY, 1999, p.14). Trata-se de um problema que nos iguala, ou seja, permite que possamos recomeçar ou nos reconstruir.

Essa reconstrução poderia partir do reconhecimento dos limites ontológicos dos saberes em relação à subjetividade dos sujeitos. $\mathrm{O}$ que significa colocar em suspensão/amputação uma das características na constituição dos saberes, ou seja, a generalização. A título de exemplo, podemos pensar nas nosografias que classificam as doenças em relação a um sujeito doente estatisticamente 
posicionado numa média entre aqueles que têm e aqueles que não têm certas características. Trata-se de um modelo uniformizador que não capta as diferenças.

\section{RASURANDO FRONTEIRAS ENTRE NÚCLEOS PROFISSIONAIS}

Façamos um exercício de memória, lembrando outras disciplinas que têm atuado na assistência em saúde - eu diria que, talvez, sem tantas crises, sem tantos receios. Vejamos, por exemplo, algumas especialidades nas suas vertentes mais tradicionais.

O serviço social, numa situação de assistência no hospital ou na unidade básica de saúde, vai atender a uma série de situações ligadas às redes sociais e institucionais, sejam elas familiares, sejam trabalhistas ou até mesmo hospitalares.

Caso estivéssemos pensando em um@ profissional da fisioterapia que estivesse se ocupando de um@4 usuári@ com problemas respiratórios, el@ realizaria procedimentos, manobras e técnicas de reabilitação e ensinaria essas mesmas técnicas para que @ paciente ou familiares pudessem realizá-las mesmo sem sua presença.

Para a enfermagem, administrar a medicação, verificar as funções vitais, explicar e realizar curativos são procedimentos que fazem parte de seu saber-fazer. Parece nem ser preciso citar @s médic@s ou outr@s profissionais da saúde, na medida em que todos nós já reconhecemos um saber-fazer consagrado e legitimado ao longo dos anos.

A educação física, na sua vertente mais biológica também adotou, ou melhor, transferiu para suas práticas de intervenção esse modelo preventivo-curativo, ao não olhar ou não escutar, enfim, ao não reconhecer que ali há um trabalho vivo a ser realizado; optou por caminhos totalizantes, em que determinadas formas de viver são boas para todas as pessoas.

${ }^{4} \mathrm{O}$ símbolo @ será utilizado ao longo do texto para se referir a ambos os sexos.

Movimento, Porto Alegre, v. 17, n. 03, p. 269-287, jul/set de 2011. 
Trata-se de um saber-fazer linear, sem tensionamento. Isso, porém, torna extremamente fácil cair na armadilha e na tentação de atender a demanda social tal qual ela se apresenta em sua aparência - cair na prática do real, ou seja, consertar um corpo estragado, no nível do imaginário, abrindo, assim, o espaço para uma constante culpabilização do indivíduo.

As práticas curativas habituais remetem @s profissionais e @s usuários/as a uma multiplicidade clínica de estudos, exames, diagnósticos, tratamentos e orientações que pode servir às equipes de saúde como uma verdadeira teia de procedimentos burocráticos e telegráficos.

Frente à impotência de curar, os profissionais de saúde buscam se sustentar na onipotência do discurso científico-técnico, preenchendo os buracos da cadeia significante com um saber que pretende eliminar a falha do sujeito, recobri-la com um nome (diagnóstico) e, em certa medida, resolvê-la (curá-la). Quando se procede assim, a repercussão nos sujeitos impede uma dose de prudência, uma vez que o desejo de suturar o que dói é mais poderoso que a modéstia de quem tem a função do cuidado.

A convicção de que a linha terapêutica será mantida se cada um fizer a sua parte bem feita (@ pediatra, @ assistente social, @ fisioterapeuta, @ professor/a de educação física, etc.) é uma ficção que faz a prática clínica equivaler a uma linha de montagem industrial em que cada operário coloca a peça e ajusta a porca correspondente. Desconhece-se, assim, que o paciente humano excede o "mecano" e se articula numa subjetividade que lhe dá suporte e que fundamenta a própria prática cuidadora.

Interessa-me pensar que tais práticas, definidas como as especificidades de cada núcleo profissional, funcionariam bem em determinadas lógicas disciplinares, principalmente aquelas do campo biomédico, que atuam numa racionalidade prática baseada na lógica técnica-objeto.

No entanto, a reforma sanitária brasileira na década de 1980 veio a provocar diversas reações nas formações dos profissionais 
da saúde. Boa parte dessas reações dirige-se no sentido de acusar que se quer acabar com as fronteiras profissionais, que se busca a profissão única, que se quer mexer na essência da atenção à saúde. Talvez o ponto que mais desafia seja o de trazer a integralidade da assistência em saúde para o horizonte das formações profissionais e, principalmente, para os modos de intervenção, o que requer uma alteração nas maneiras de olhar, com outras técnicas e outros saberes (CECCIM; FERLA, 2009).

De todos os pressupostos do SUS, desde a universalidade e a hierarquização até a eqüidade, o mais problemático é o da integralidade, na medida em que este pressuposto exige o conjunto articulado e contínuo de ações e serviços preventivos e curativos, individuais e coletivos, exigidos para cada caso, em todos os níveis de complexidade do sistema. Mesclam-se, aí, ações de promoção, proteção e recuperação de agravos à saúde que, diante da complexidade que se faz presente, exigem a atuação de pessoas com diferentes especialidades e capacitações.

Assim, cabe situar a integralidade na perspectiva da subjetividade. De acordo com Mary Jane Spink, trata-se de entendêla

como processo de negociação de sentidos da demanda. Em uma perspectiva discursiva, a demanda é uma mescla de direitos, necessidades e desejos, que assumem conotações distintas, de acordo com o processo específico de interanimação dialógica. Essas trocas discursivas, que mesclam socialidades e materialidades, ocorrem em contextos definidos pelas posições de pessoas que se fazem presentes (SPINK, 2007, p. 27).

A integralidade, portanto, é da ordem do borramento de fronteiras, ou melhor, da rasura disciplinar, e envolve múltiplas especialidades que se entrecruzam para dar resposta a demandas e necessidades. A atenção à saúde, que encerra todo o conjunto de ações levadas a efeito pelo SUS, em todos os níveis de governo, para o atendimento das demandas pessoais e das exigências 
ambientais, compreende três grandes campos, a saber: o da assistência; o das intervenções ambientais; e o das políticas externas ao setor saúde.

No núcleo da educação física e das outras áreas profissionais, vem se acirrando uma divisão em dois blocos ideológicos: o da manutenção do status quo, referenciado no modelo flexeneriano da formação médica e do complexo industrial, e o da mudança, que recebe influências das lutas históricas do movimento sanitário brasileiro, das lutas de usuários, organizações da sociedade civil, trabalhadores da saúde etc.

$\mathrm{O}$ fato de a integralidade ser uma ferramenta que exige torções e redimensionamentos que mexem nas entranhas do instituído não é uma exclusividade da área da educação física. Se fosse uma ferramenta de vasta aceitação, não teríamos diretrizes curriculares na graduação prescrevendo que todos os cursos da saúde devem ser atravessados pela integralidade, nem grupos produzindo pesquisas e estudos, como o Laboratório de Pesquisas sobre Práticas em Integralidade em Saúde (LAPPIS), nem políticas advindas do Ministério da Saúde que buscam informar e qualificar o setor para a integralidade, como o Ver-SUS, Humaniza-SUS ou o Aprender-SUS.

Talvez o maior mérito da noção/conceito de integralidade seja o de permitir que realizemos nossas inserções clínicas a partir de e com as referências teóricas do profissional que é chamado a intervir. Isso desde que a intervenção esteja baseada em uma teoria do sujeito e não de uma teoria do objeto. Nas palavras de Ricardo Ceccim e Alcindo Ferla:

A atenção integral à saúde não corresponde ao acesso às tecnologias biocientíficas, mas ao domínio dos fatores de condicionamento dos estados de saúde e às chances de intervenção oportuna ou adequada sobre os mesmos. A busca das possibilidades de articulação entre ação política e novos paradigmas científicos, a justa tradução entre informação biocientíficas e práticas terapêuticas, a transposição entre evidência epidemiológica e narrativa do processo saúde-doença, entre outros fatores 
capazes de auxiliar na escuta, cuidado e tratamento de pessoas e coletivos e na superação das crises setoriais construíram uma referência social ao pensamento intelectual da área (CECCIM; FERLA, 2009, p.447).

A possibilidade/radicalidade de mudança na clínica em saúde coletiva depende de algumas mutações fundamentais nas matrizes formativas, no sentido de potencializar a intervenção para e com o conceito ampliado de saúde.

\section{ENTRE O JOGO DE XADREZ E O FRESCOBOL ${ }^{5}$}

Pensemos numa situação hipotética, que poderia acontecer em uma unidade básica de saúde ou em um centro de atenção à saúde mental: um usuário de 25 anos, homem com transtornos mentais. A equipe, em seu projeto terapêutico, propõe/combina que diferentes membros da equipe o acompanhem em uma série de situações cotidianas, reinserindo-o na trama social.

Trata-se de um deslocamento de dentro das paredes da instituição para o excêntrico, para a rua, inserindo-se nas trocas sociais da comunidade. Isso implica estar na rua, diante de todos os percalços e desvios nos caminhos que se enfrentam no processo saúde-doença - amarrar seus próprios sapatos, fritar um ovo, atravessar uma via pública, situações estranhas, como tantas outras da cidade em que se vive.

Supondo-se que uma das possíveis situações seria a tarefa de auxiliar um usuário que perdera os documentos: O que pode significar isso? Que situações estão em jogo? Como se faz essa intervenção para que tenha sentido? Uma das propostas que o usuário contratou com a equipe é a de refazer a carteira de identidade... As reticências

\footnotetext{
${ }^{5} \mathrm{No}$ jogo de frescobol recreativo ou competitivo o que importa é manter a bola no ar sendo rebatida pelos participantes (dois, três ou até quatro jogadores) o maior tempo possível; dependendo do nível dos jogadores pode-se combinar que as bolas possam ser atacadas e defendidas, que jogadas sejam mais rápidas ou mais lentas. Como se joga cooperativamente, não há adversários e sim parceiros. É um jogo em que é cultivado o comprometimento entre os parceiros nas jogadas.
} 
aqui são para que o leitor possa fazer seu trajeto, pensar como ele faria, que questões surgiriam, enquanto me detenho em alguns pressupostos da intervenção.

Um deles tem a ver com o pedido de ajuda, mais especificamente, quanto à concepção do adoecer. Neste ponto, recorro às palavras de Ana Figueiredo:

Quem adoece e sofre é, antes de tudo, um sujeito e não um corpo. Logo, a fala deve ser privilegiada não como uma manifestação patológica que exige correção ou resposta imediata, mas como possibilidade de fazer aparecer uma outra dimensão da queixa que singulariza o pedido de ajuda (FIGUEIREDO, 1997, p.43).

Para realizar essa conexão com o pedido de ajuda, é preciso desmedicalizar a demanda e escutar a subjetividade que está na fala do usuário. Outro ponto fundamental é constituir uma equipe que realize permanentemente a discussão, que consiga romper com as hierarquias burocráticas, disciplinares e funcionais, para abrir-se para o aprofundamento nas micropolíticas do trabalho em saúde.

$\mathrm{Na}$ medida em que possamos partir de uma equipe continente e acolhedora, o ato de acompanhar o usuário em seu caminho em direção à carteira de identidade modifica-se, torna-se parte de um projeto terapêutico que envolve o próprio sujeito, seus familiares e sua comunidade. Desse modo, acompanhá-lo ganha outras significações, pois não se trata apenas de um documento, como um objeto burocrático, mas da construção do caminho junto com ele. Trata-se de construir hipóteses juntos, de errar os caminhos, de voltar para casa sem conseguir, de poder suportar as "esquisitices" do sujeito. Trata-se de colocar-se no lugar do objeto que o sujeito demanda, introduzir ali as demandas correspondentes no momento adequado, fazer-se de marco que sustente o andar e saber reordenar o saber que ele tem da vida.

Voltando ao itinerário, a possibilidade de acompanhar, produzindo um ato terapêutico, e de criar e construir junto com o sujeito, são condições necessárias para que o trabalho ocorra, num processo 
que tem efeitos em ambas as partes implicadas, sujeito-usuário e sujeito-profissional. Como num jogo de xadrez, em que tenhamos apenas as primeiras jogadas (entradas) e que, depois, usuário e acompanhante tentem jogar, cada um de seu jeito, jogada após jogada. Assim como no jogo de xadrez, "na rua", só podemos dizer o que se passará ao final de cada encontro, nunca de antemão. Esta é a difícil posição a ser sustentada pel@ trabalhador@ de saúde, que está sempre em contato com a diferença e com o inesperado, com as condições de angústia e prazer desse ofício.

Tocando essa questão, diria, sobre os encontros iniciais, que o delineamento da figura (e da função) d@ acompanhante está intimamente relacionado com uma discussão sobre sua posição posição frente ao/à falante e/em sua fala -, e não sobre possíveis fatores etiológicos, como tem sido o caso. Nesse sentido, a analogia empreendida por Freud (1996, vol. XII) entre o jogo de xadrez e o manejo do clínico na entrevista pode ajudar nessa reflexão. $\mathrm{O}$ autor nos diz que saber jogar xadrez é saber marcar posições frente às jogadas do outro (mais do que conhecer as regras do jogo de xadrez).

Nas palavras de Freud:

Todo aquele que espera aprender o nobre jogo de xadrez nos livros, cedo descobrirá que somente as aberturas e os finais de jogos admitem uma apresentação sistemática exaustiva e que a infinita variedade de jogadas que se desenvolvem após a abertura desafia qualquer descrição desse tipo. Esta lacuna na instrução só pode ser preenchida por um estudo diligente dos jogos travados pelos mestres. As regras que podem ser estabelecidas para o exercício do tratamento psicanalítico acham-se sujeitas a limitações semelhantes (FREUD, 1996, p. 241).

Em outras palavras, o modo de condução de um encontro fora das paredes protegidas de uma instituição de saúde decorre "do que se escuta", ou melhor, do efeito de um corpo-teórico (que precisa da noção de "escuta") no corpo-do-cuidador na sua escuta. 
Outra metáfora que pode ajudar @ professor/a de educação física e/ou outr@s profissionais com relação ao prosseguimento do trabalho é a passagem/transição de um jogo de xadrez para o jogo do frescobol. No jogo de frescobol, não há um@vencedor@, e @s parceir@as têm que, aos poucos, achar o melhor modo de a bola não cair, sua força e altura, a cada jogada, a cada lance.

No decorrer da partida (seguindo a metáfora), as jogadas são infinitas. Então, cada tratamento é único, e as estratégias validamse a partir da regra fundamental que rege a situação terapêutica. Portanto, as jogadas encontram sua validade no fato de aproximar mais ou afastar menos da entrada em campo da fala do sujeito usuário, de seu gestual e da escuta de seu acompanhante.

Cabe aqui, neste ponto da discussão, pensar que a atenção baseada na integralidade depende da legitimidade que determinad@s profissionais detêm como resultados das batalhas travadas no interior das equipes de saúde - quem está mais autorizado a escutar os discursos que operam a partir de regras, que são dadas por um conjunto de questões; quem pode falar; o que pode falar; para quem; em quais circunstâncias.

Sobre a especificidade da educação física, enquanto núcleo profissional, no âmbito das intervenções em saúde coletiva, ela pode existir ou não, dependendo do que ocorre num encontro entre o cuidador e o usuário. É preciso ressaltar, ainda, que qualquer formação disciplinar acaba por desenvolver certa sensibilidade para alguma dimensão da cultura, seja ela corporal ou não. E que somente durante os encontros, com seus mistérios relacionais é que descobriremos se uma poesia, música, dança ou a bola consigam produzir aquele momento intensamente rico de produção de subjetividades e, portanto, de cuidado que pode vir de nossa valise disciplinar, ou aprendida ao longo da vida em outras experiências.

Assim, talvez possamos fazer valer as belas palavras de Emerson Merhy (1997, p. 2) sobre o trabalho vivo, "abrir-se para os ruídos presentes no seu cotidiano, com isso, e de posse de uma caixa de ferramentas que tenha o compromisso com o sujeito da ação, 
pode-se reinventar a lógica do processo de trabalho" em saúde coletiva e permitir uma escuta não-normalizadora, mas um agir potente e criativo.

Para finalizar, busquei articular neste ensaio um conjunto de ideias através do uso de três metáforas (amputação, jogo de xadrez, jogo de frescobol). O esforço empreendido foi no sentido de empoderar o núcleo da educação física no sentido de utilizar outras ferramentas que estão presentes na capacidade interrogativa da integralidade. Para tanto, é preciso que o agir terapêutico ultrapasse as fronteiras, que elas sejam no mínimo borradas ou rasuradas, como no título que dá nome a este texto.

No caso da amputação, proponho um ato cirúrgico, que elimina o fazer técnico específico da área como uma instância curativa por si mesma. Em relação ao jogo de xadrez, importa dizer que apenas os primeiros movimentos podem ser antecipados ou previstos. E por fim, com o frescobol, a ideia de que o fazer terapêutico é potencializado a cada ação do outro.

Sem dúvida, que a incorporação do dispositivo da integralidade mexe nas entranhas do instituído, traz incertezas e exige torções constantes na produção de atos de saúde. Ao mesmo tempo, que se colocada em ato a integralidade pode levar a reinvenção e a humanidade como potências de vida e de saúde.

Assim, a inserção da educação física a partir da integralidade procuraria deixar-se tomar pelas diferenças entre cada sujeito e produziria um projeto terapêutico levando em conta as condições de vida e as jogadas subjetivas possíveis em cada momento. 
Erasures disciplinary and amputation from doing

Abstract: This essay reflects on some possibilities of physical educator acting in the field of collective health, from the logic of integrality in health. The text attempts to tension some central points in the hegemonic logic of discourses involving physical activities and health in the area of physical education. I have suggested that overcoming this picture requires the amputation of a disciplinary knowledge that has established subject-object relationships, in order to allow for a non-medical view of the demand and hearing the subjectivity that underlies the individuals' complaints.

Keywords: physical education. Health. Integrality. hearing.

Tachaduras disciplinaria y la amputación de hacer

Resumen: El ensayo haz una reflexión sobre algunas posibilidades de los profesionales de educación física actuaren en el campo de la salud colectiva con base en la lógica de la integralidad en la salud. Busca poner en tensión algunos puntos centrales en la lógica hegemónica de los discursos direccionados a la actividad física y salud en el área de la educación física. Sugiere que la superación de ese cuadro demanda una cirugía de amputación del saber disciplinar que establece relaciones sujeto-objeto para que se pueda desmedicalizar la demanda y escuchar la subjetividad que está en la queja de los individuos. Palabras clave: educación física. salud colectiva. integralidad y escucha 


\section{REFERÊNCIAS}

BAREFOOT. John C, Alcoholic beverage preference, diet, and health habits in the UNC Alumni Heart Study. Journal Clinical Nutrition, n. 76, p. 466 - 472, aug 2002

BILILIBIO, Luis Fernando. DAMICO, José Geraldo. Carta à um jovem Professor. Cadernos de Formação RBCE, p. 92-103, jul. 2011.

CARREIRA, Shirley. O não-lugar da escritura: uma leitura de Ensaio sobre a Cegueira, de José Saramago. Letras \& Letras (UFU), p. 28-41, 2001.

CASTIEL, David. Quem vive mais morre menos? Estilo de riscos e promoção da saúde. In: PALMA, ESTEVÃO; BAGRICHEVSKY (Org.). Saúde em debate na educação física. Blumenau: Edibes, 2003.

CECCIM, Ricardo Burg; FERLA, Alcindo Antônio. Educação e saúde: ensino e cidadania como travessia de fronteiras. Trab. Educ. Saúde, v. 6 n. 3, p. 443-456, nov.2008/fev.2009.

FENSTERSEIFER, Paulo. Evaldo. Corporeidade e formação do profissional na área da saúde. Revista Brasileira de Ciências do Esporte, Campinas - SP, v. 27, n. 3, p. 93-102, 2006.

FIGUEIREDO, Ana. Vastas confusões e atendimentos imperfeitos. Rio de Janeiro: Relume-Dumará, 1997.

FRAGA, Alex. Exercício da informação: governo dos corpos no mercado da vida ativa. Campinas, SP: Autores Associados, 2006.

FRANCO, Túlio; MERHY, Emerson. Produção imaginária da demanda. In: Pinheiro, R.; MATTOS, R. A. (Org.) Construção social da demanda. Rio de Janeiro: IMS/ UERJ-CEPESC-ABRASCO, p. 181-194, 2005.

FREUD, Sigmund. O caso Schreber, artigos sobre técnica e outros trabalhos (19111913). In: OBRAS psicológicas de completas de Sigmund Freud. Rio de Janeiro: Imago, 1996. v. 12.

Estudos sobre a Histeria. Tradução J. Salomão. In: OBRAS psicológicas completas. Rio de Janeiro: Imago, 1983. v. 2. Edição Standard Brasileira. Original publicado em 1893.

HADDAD, Ana Estela (Org.). A trajetória dos cursos de graduação na área da saúde: 1991-2004. Brasília: Instituto Nacional de Estudos e Pesquisas Educacionais Anísio Teixeira, 2006.

KRIS-ETHERTON, Nicolosi. Trans-Fatty Acids and Coronary Heart Disease Risk. Amer Clin Nutr, n. 62, p. 652-708, 2005.

JERUZALINSKY, Alfredo. Psicanálise e desenvolvimento infantil: um enfoque trandisciplinar. Porto Alegre: Artes e Ofícios, 1999. 
MERHY, Emerson. Agir em saúde: um desafio para o público. São Paulo: Hucitec, 1997.

OLIVEIRA, Dora. A 'nova' saúde pública e a promoção da saúde via educação: entre a tradição e a inovação. Revista Latino-Americana de Enfermagem, Ribeirão Preto, v. 13, n. 3, p. 423-431, 2005.

SCARMEAS, N.; LEVY, G.; STERN, Y. Influence of leisure activity on the incidence of Alzheimer's. Disease Neurology, n. 57, p. 2236-2242, dec. 2001.

SPINK, Mary Jane. Sobre a possibilidade de conciliação do ideal da integralidade nos cuidados à saúde e a cacofonia da demanda. Saude soc., v. 16, n. 1, p. 1827, 2007.

ZANELLO, Valeska. Metáfora e transferência. Psicologia: Reflexão e Crítica, v. 20, n. 1, p. 132-137, 2007.

Endereço para correspondência:

José Damico

Trav. Nossa Senhora de Lourdes 230/apto 501C

Bairro Tristeza

CEP: 91920-040 Porto Alegre - RS

Recebido em: 18.07.2011

Aprovado em: 07.10.2011

Movimento, Porto Alegre, v. 17, n. 03, p. 269-287, jul/set de 2011. 
